\title{
Deformación de Branquias en Salmónidos: Análisis Macroscópico, Histológico, Ultraestructural y de Elementos
}

\author{
Gill Deformation in Salmonids: Macroscopic, Histological, Ultrastructural and Elements Analysis
}

\author{
*,*** Ignacio Roa; *Rodrigo Castro \& **Mariana Rojas
}

ROA, I.; CASTRO, R. \& ROJAS, M. Deformación de branquias en salmónidos: Análisis macroscópico, histológico, ultraestructural y de elementos. Int. J. Morphol., 29(1):45-51, 2011.

RESUMEN: Las branquias son los órganos destinados al proceso de respiración en los peces, estas están consideradas, entre las estructuras más delicadas del cuerpo de los teleósteos ya que están expuestas a sufrir daños de cualquier agente irritante, los cuales constituyen la causa más frecuente y significativa de sus cambios patológicos. Los objetivos del presente estudio son caracterizar las alteraciones branquiales desde los puntos de vista anatómico, histológico, además, determinar niveles de Ca, P y Zn del tejido óseo de la columna vertebral y cráneo de salmones afectados. Se utilizaron 47 salmones, divididos en dos grupos: control y con deformaciones, a los cuales se les realizaron análisis macroscópico, histológico, ultraestructural y de elementos. Se observaron alteraciones tanto en el contexto anatómico como histológico, así como gran presencia de bacterias y hongos que afectaban principalmente al primer arco, pudiendo concluir que los peces tendrían una susceptibilidad génica a la deformación branquial.

PALABRAS CLAVE: Salmónidos; Branquias; Deformación.

\section{INTRODUCCIÓN}

Las branquias son los órganos destinados al proceso de respiración en los peces. Estas estructuras son las encargadas de realizar el intercambio gaseoso, las cuales están consideradas como las más delicadas del cuerpo de los teleósteos, lo que se debe a su localización externa y su necesario e íntimo contacto con el agua, por lo que están expuestas a sufrir daños de cualquier agente irritante, disuelto o en suspensión en el agua, siendo los irritantes externos son la causa más frecuente y significativa de sus cambios patológicos (González \& Valladolid, 1998).

Frente a altas concentraciones de contaminantes químicos irritantes, como son los metales pesados y ciertos pesticidas, así como frente a una sobredosis de formol, las branquias reaccionan con un edema generalizado, especialmente intenso en la base de las laminillas secundarias, debido a un aumento de la permeabilidad capilar (Roberts, 1981). Cuando el edema aumenta se produce a una separación completa del epitelio respiratorio de las laminillas primarias y secundarias, provocando necrosis de las células del epitelio laminar, pudiendo sobrevenir un síndrome severo y, a veces, letal, por alteración de la respiración y osmorregulación (Roberts). Estos mismos irritantes en bajas concentraciones u otras sustancias, como el amoníaco o el dicloro difenil tricloroetano (DDT), producen una hiperplasia que conduce a cambios de proliferación durante largos períodos, los cuales normalmente son imposibles de distinguir de los cambios proliferativos que produce la irritación ejercida por los cuerpos sólidos en suspensión (Kinkelin et al., 1991).

Las branquias además, pueden presentar patologías específicas como por ejemplo las de origen micótico, denominada branquiomicosis. Una de las especies de hongos que se puede localizar en las branquias es Saprolegnia parasitica, que invade al pez desde la superficie y no por vía vascular como otras especies. La muerte es mucho más rápida cuando Saprolegnia invade las branquias que cuando afecta a la piel, debido a la gran vascularización del tejido de las laminillas de las branquias y a su importancia en el control de la respiración y regulación de la osmosis (Roberts).

\footnotetext{
* Programa Magíster en Ciencias Biológicas, Facultad de Medicina, Universidad de Chile.

** Programa de Anatomía y Biología del Desarrollo Facultad de Medicina, Universidad de Chile.

**** Unidad de Anatomía Normal, Universidad de Talca, Chile.
} 
Las lesiones branquiales asociadas a infestaciones parasitarias varían según el agente causal, el huésped y la intensidad de la invasión. Muchos parásitos, como los crustáceos Ichthiophthirius multifiliis y la gloquidia de los mejillones, son agentes primarios pero muchos otros invaden las lesiones crónicas producto de una irritación por amoníaco o por partículas en suspensión (Kinkelin et al.). Los restos celulares y secreciones mucosas van proporcionando un suplemento nutritivo en un tejido ya debilitado. En la mayor parte de las lesiones por protozoarios se acompañan solamente de algunos signos de necrosis focal con ligero edema. Los parásitos patógenos primarios, especialmente los metazoarios, producen lesiones mucho más severas.

Otra causa de patologías branquiales son las interacciones entre minerales, en la práctica piscícola suelen presentarse signos de carencia de minerales debido a desequilibrios en el contenido de calcio, provocados por el efecto antagonista del exceso de calcio en la dieta sobre la absorción de fósforo y de minerales traza como zinc, hierro y manganeso.

Las alteraciones óseas pueden ocurrir por deficiencia de triptófano, magnesio, fósforo, vitamina $\mathrm{C}$, ácidos grasos esenciales (lordosis) o por toxicidad por plomo, cadmio, leucina, vitamina A (FAO, 2010).

Se han presentado deformaciones en las branquias de salmones criados en un gran número de pisciculturas de Puerto Montt, Chile. Esta patología afecta aproximadamente al $30 \%$ de la población y no está descrita en la literatura. Los objetivos del presente estudio son los siguientes: 1) caracterizar anatómicamente la deformación de las branquias, reconociendo si se trata de una alteración uni o bilateral, determinando el número de arcos branquiales involucrados e identificando el nivel en el cual está afectado, como también el grado de severidad. 2) Analizar el tejido branquial mediante microscopía óptica y electrónica para visualizar microorganismos y características citológicas de las laminillas branquiales. 3) Determinar niveles de $\mathrm{Ca}, \mathrm{P}$ y $\mathrm{Zn}$ del tejido óseo de la columna vertebral y cráneo de salmones afectados.

\section{MATERIAL Y MÉTODO}

Se estudiaron cuarenta y siete salmones provenientes de dos pisciculturas de Puerto Montt, Chile: de los cuales 24 pertenecían al grupo control y 23 al grupo con deformación en las branquias, estos poseían un tamaño que fluctúa entre 33 y $57 \mathrm{~cm}$ y 28 y $68 \mathrm{~cm}$, respectivamente. Las 2 muestras se dividieron en tres subgrupos: I) conformado por 28 peces congelados en su lugar de origen, II) conformado por 15 peces fijados en formalina al $10 \%$ y III) conformados por 4 peces fijados en glutaraldehido al $2 \%$. Los salmones del subgrupo I, fueron disectados e inspeccionados en detalle para observar las características de órganos, tejidos y estado general del cuerpo. De cada salmón se obtuvo el esqueleto óseo de la cabeza y la columna vertebral para un análisis químico proximal con el fin de determinar el porcentaje de calcio, fósforo y zinc. Con los resultados obtenidos, se compararon los valores entre las muestras que presentan la deformación y los controles.

Las muestras del subgrupo II (fijadas en formalina al $10 \%$ ) se procesaron y destinaron a estudio histológico. Las técnicas utilizadas fueron las siguientes: HematoxilinaEosina azul de Alcian, Tricrómico de Masson (para evidenciar fibras colágenas) y técnica de Von Kossa (para la detección de depósitos de calcio). Además se utilizó la técnica de transparentado descrita por Hanken \& Wassersug (1981) para analizar el proceso de condrificación y osteogénesis de las branquias.

Las muestras del subgrupo III, fijadas en glutaraldehido al $2 \%$, se posfijaron en tetróxido de osmio y se procesaron para microscopía electrónica de transmisión. Luego se realizaron cortes semifinos de chequeo de $1 \mathrm{~mm}$ de espesor y se tiñeron con azul de toluidina para elegir el área a estudiar. Posteriormente se hicieron cortes ultrafinos los cuales se tiñeron con acetato de uranilo y se observaron en microscopio electrónico de transmisión (Zeiss EM -109).

\section{RESULTADOS}

En los salmones congelados (grupo I): no se observaron diferencias macroscópicas entre los grupos control y deformados, considerando longitud del cuerpo, color, textura, características de la piel, tejido muscular, disposición de la columna vertebral. Los órganos internos (hígado, riñones, vesícula, corazón, vejiga natatoria, tubo digestivo) no presentan alteraciones visibles a simple vista. Las gónadas son apenas diferenciables dificultando la determinación del sexo.

Análisis químico proximal. El porcentaje de Ca y $\mathrm{P}$ como también la relación $\mathrm{Ca} / \mathrm{P}$ se encuentra dentro de los rangos de normalidad, tanto para salmones controles como para aquellos que presentan la alteración. El porcentaje de Zn resultó más elevado en los salmones con deformación en uno de los grupos (Tabla I). 
Tabla I. Porcentaje sobre la base de materia seca de calcio (Ca), fósforo (P), y zinc ( $\mathrm{Zn}$ ) del esqueleto óseo.

\begin{tabular}{lcccccc}
\hline Tamaño & Tipo de Muestra & Materia Seca & \% Ca & \%P & Zn mg/kg & \% Cenizas \\
\hline $28-35 \mathrm{~cm}$ & Controles & $42,7 \pm 0,7$ & $8,7 \pm 0,7$ & $5,2 \pm 0,3$ & $167 \pm 58$ & $25 \pm 1,2$ \\
$28-35 \mathrm{~cm}$ & Patológicos & $42,0 \pm 1,9$ & $8,5 \pm 1$ & $5,2 \pm 0,4$ & $177 \pm 28,2$ & $25 \pm 1,8$ \\
$57-68 \mathrm{~cm}$ & Controles & $75,0 \pm 9,8$ & $4,5 \pm 0,4$ & $3,4 \pm 0,4$ & $127 \pm 24,7$ & $16,5 \pm 1,4$ \\
$57-68 \mathrm{~cm}$ & Patológicos & $58,9 \pm 2,9$ & $5,7 \pm 0,7$ & $4,4 \pm 0,5$ & $88 \pm 12,3$ & $20,8 \pm 2,3$ \\
& & & & $100 \%$ & & \\
\hline
\end{tabular}

Descripción macroscópica de las branquias. En la figura 1 se indican las características de las branquias de un salmón control. En la figura 2 se puede observar una inflexión
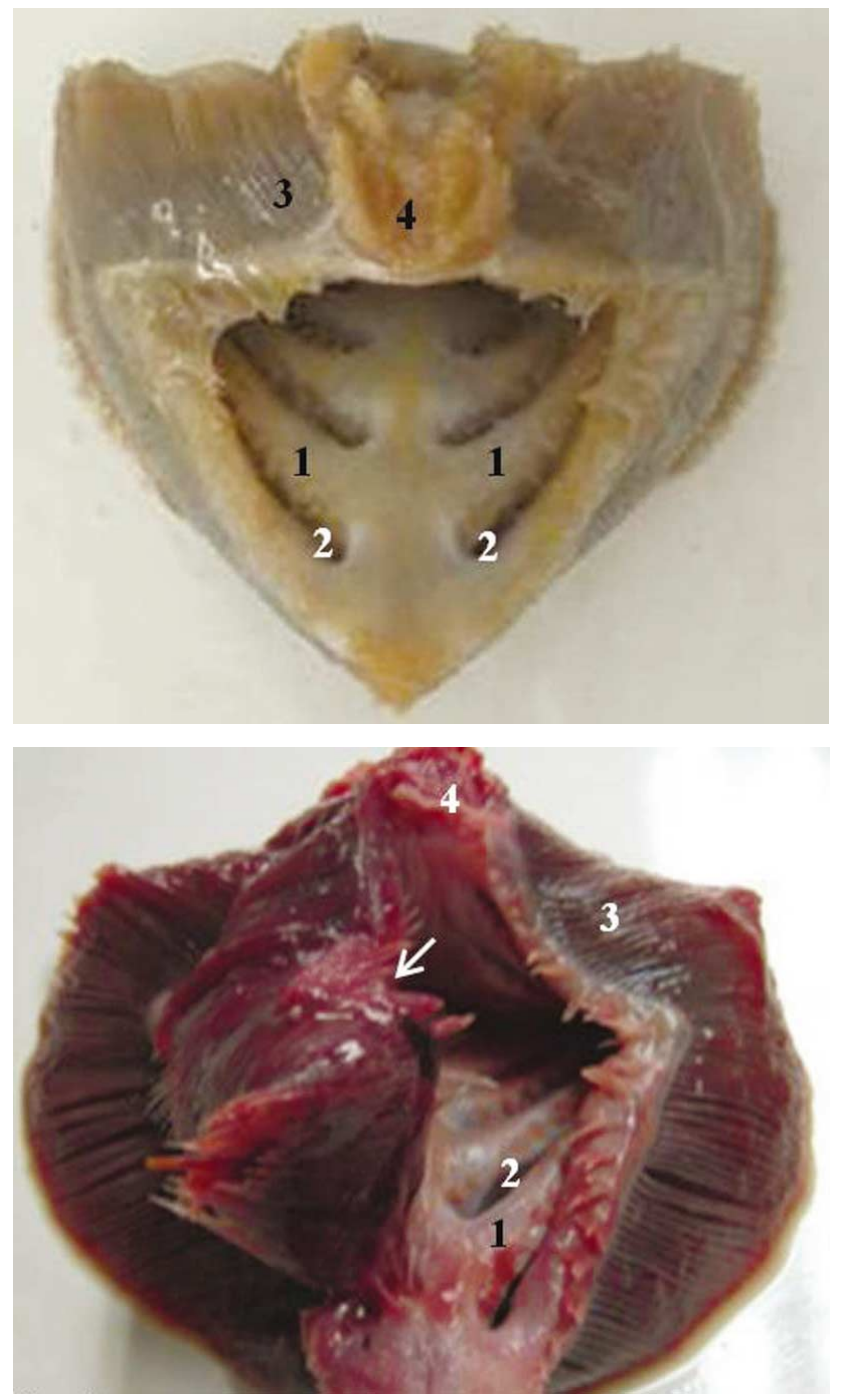

Figs. 1. y 2. Vista macroscópica de la región branquial normal y deformada, respectivamente, se aprecian: arcos branquiales (1); hendiduras branquiales (2); hilera de filamentos (3); inserción en base del cráneo (4), se puede observar una inflexión anormal de la primera branquia derecha (flecha). anormal de la primera branquia derecha (ver flecha), resultando en una proyección hacia la faringe y boca. Esta alteración es unilateral en una de las muestras, mientras que en la otra se presenta bilateral, siempre afectando la primera branquia. El resto de los arcos no presentan alteración, así como tampoco las demás estructuras que conforman la branquia.

Descripción mesoscópica. En las branquias se pueden evidenciar deformaciones unilaterales (Fig. 3) o bilaterales. La branquia deformada puede presentar uno o varios puntos en los cuales no se visualiza hueso ni cartílago (ver flechas). El color rojo oscuro destaca el tejido óseo calcificado, mientras que el color azul marca los glicosaminoglicanos del cartílago.
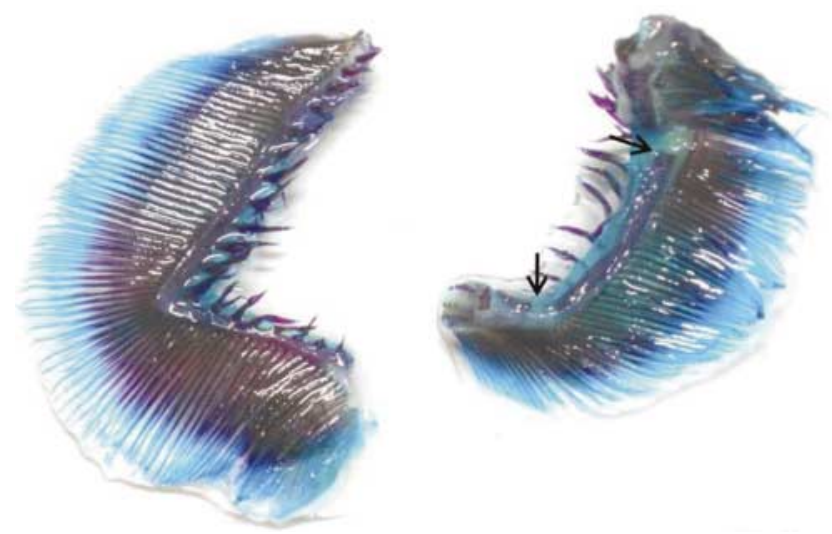

Fig. 3. Branquias obtenidas de un mismo salmón, en la cual se aprecia: branquia derecha deformada e izquierda normal, Diafanizada mediante técnica de Hanken \& Wassersug. Las flechas indican soluciones de continuidad de cartílago y hueso.

Entre las laminillas defectuosas existe un mucus azul de Alcian positivo, lo que indicaría una secreción rica en glucosaminoglicanos que pega a las laminillas entre sí.

Las articulaciones de las laminillas branquiales aparecen dispuestas en dirección contraria a lo normal generando la rotación de la branquia (Fig. 4). 


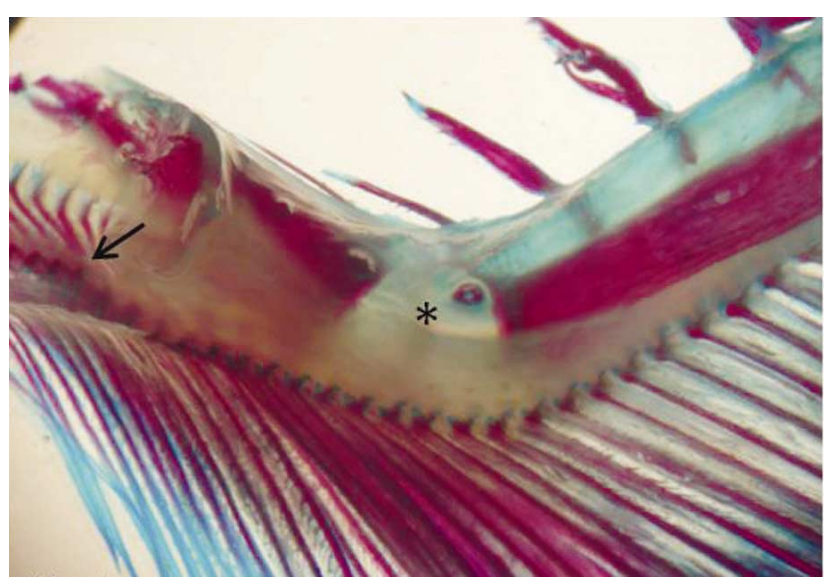

Fig. 4. Branquia deformada, laminillas branquiales rotadas (ver flecha), solución de continuidad del hueso (*). Técnica de Hanken \& Wassersug, 25X.

Descripción Histológica.En el salmón normal las laminillas branquiales se encuentran ordenadas y de un diámetro similar desde la porción proximal hasta la distal (Fig. 5a). En la figura $5 \mathrm{~b}$ se pueden diferenciar las branquias de un salmón con una patología inicial (que inicialmente clasificado como control sano) caracterizada por un aumento del diámetro en las porciones dístales de las laminillas branquiales. Al centro de la laminilla primaria se ven los nódulos de cartílago hialino ubicados en el espesor de tejido conjuntivo denso. No se observa mucus entre las laminillas.

En los cortes histológicos de salmones deformados se observa que el cartílago hialino presenta una alteración

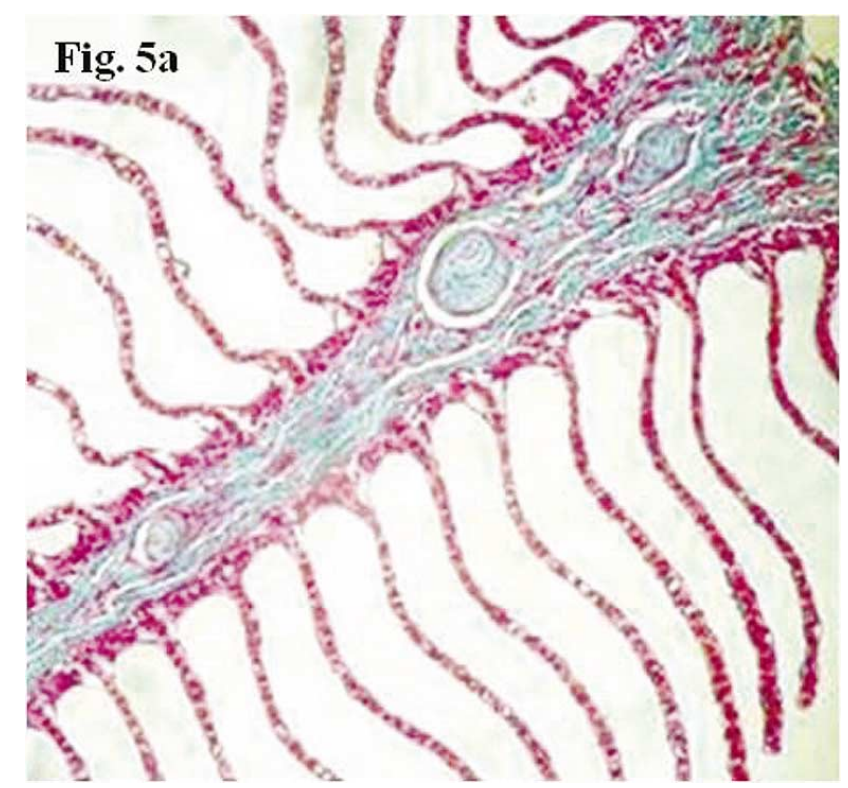

Fig. 5a. Laminillas branquiales normales. Técnica tricrómico, 100X.

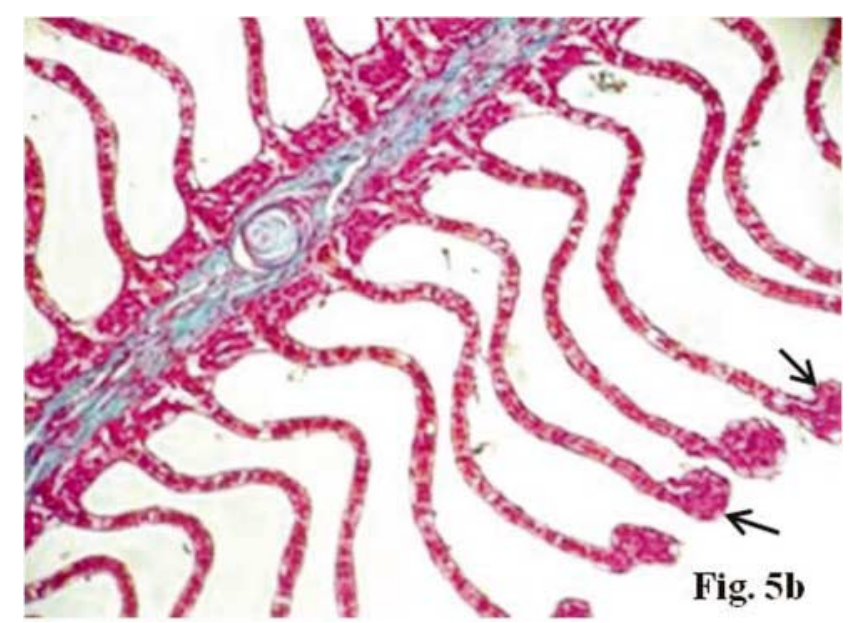

Fig. 5b. Laminillas branquiales con patología inicial en el segmento distal (flechas). Técnica tricrómico, 100X.

tanto en la matriz extracelular, como en la disposición de los condrocitos o células cartilaginosas. En algunas zonas el cartílago es completamente reemplazado por tejido fibrilar denso similar a un proceso de condrodistrofia. Además se observa una transformación de las células epiteliales que componen las laminillas branquiales en tejido fibrilar denso (transformación epiteliomesenquimática).

Se puede distinguir una importante cantidad de estructuras que no pertenecen a las branquias además de mucus PAS positivo entre las laminillas branquiales, lo que sugiere la presencia de hongos u algas (Fig. 6a). También se puede distinguir la presencia de células polimorfonucleares.

Se identifica hiperplasia general de las laminillas branquiales, la cual avanza desde el esqueleto de la branquia (Figs. 6a, 6b), hacia la porción distal de las laminillas secundarias. Entre las laminillas se identifica un aumento del mucus, eritrocitos y unas estructuras similares a ovas de hongos o algas. En la figura $6 b$, ha ocurrido metaplasia con fusión de las laminillas y se ha perdido completamente la morfología de la branquia. En relación al cartílago hialino y hueso que forma el esqueleto de las branquias se observó lo siguiente: el cartílago hialino presenta una alteración tanto en la matriz extracelular, como en la disposición de los condrocitos o células cartilaginosas, aparece neoformación de vasos sanguíneos que fraccionan al cartílago similar a un tipo de osificación periostal, pero aquí no se forma botón periostico ni ocurre osificación. En algunas zonas el tejido cartilaginoso es completamente reemplazado por tejido fibrilar denso similar a un proceso de condrodistrofia. El punto donde el cartílago hialino es discontinuo es donde ocurren las inflexiones y se deforma la branquia. 


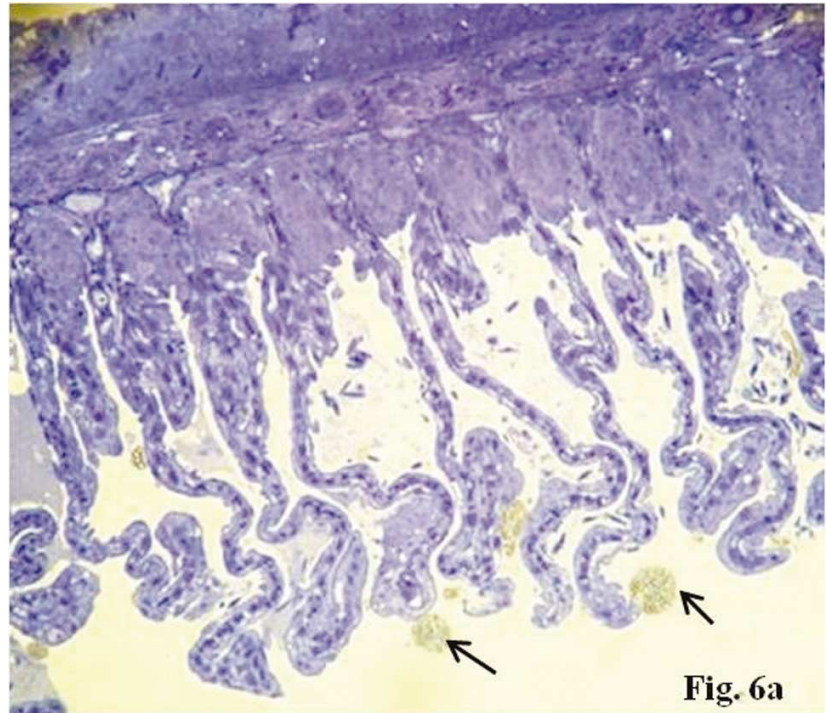

Fig. 6a. Fotomicrografía de laminillas branquiales, Las flechas indican ovas de hongos. Tinción azul de toluidina 40X.

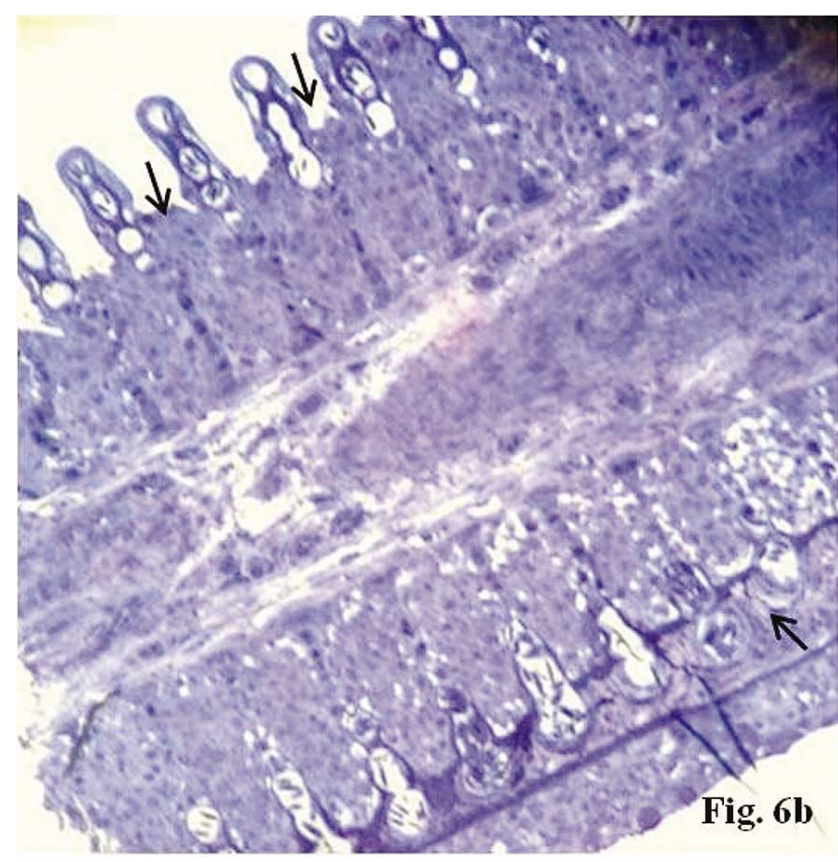

Fig. 6b. Fotomicrografía de laminillas branquiales, se observa engrosamiento de las laminillas (flechas). Tinción azul de toluidina $40 X$.

Microscopía electrónica. Se observa un gran número de bacterias con cápside entre las laminillas branquiales y también en el interior del citoplasma de macrófagos (Fig. 7a) los cuales se encuentran en regresión. Las células epiteliales de las laminillas branquiales presentan micropliegues en su superficie apical. En la figura 7b, se puede ver como estas bacterias proliferan y se aproximan a la región donde están los medios de unión para ingresar a la célula.

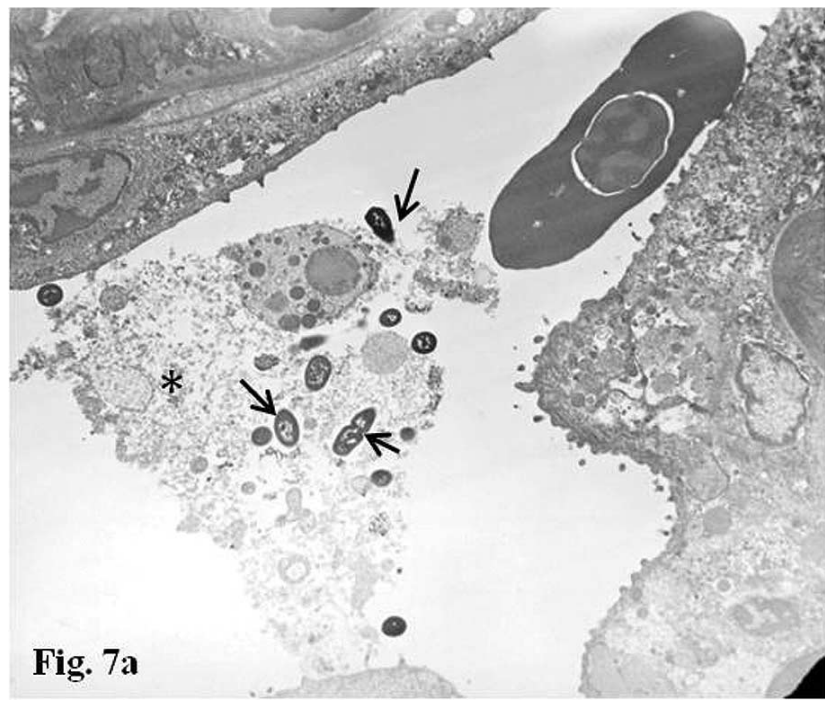

Fig. 7a. Fotomicrografía de MET. Bacterias (flechas) en el interior del citoplasma de un macrófago (*) (3000X).

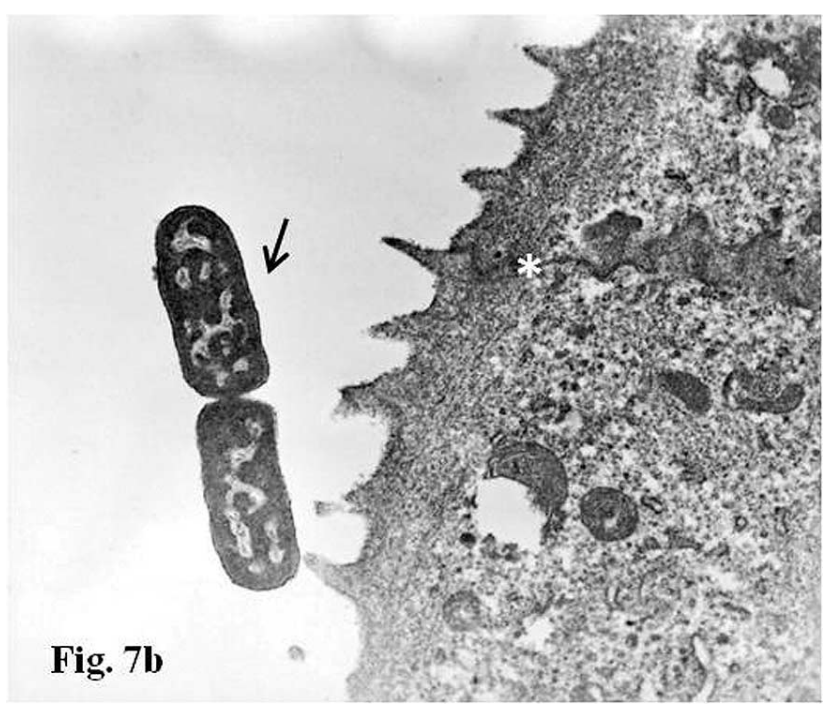

Fig. 7b. Fotomicrografía de MET. Proliferación de bacterias (flechas) cercanas a la zona de unión de las células epiteliales (*) (12.000X).

\section{DISCUSIÓN}

La branquias son órganos sensibles considerados de tipo primario, útiles para evaluar el efecto de la polución (Bernet et al., 1999) y, por lo tanto, son importantes para ser utilizados en la aplicación como biomarcadores histopatológicos (Giari et al., 2007).

Esta patología que no está descrita en la literatura como tal puede ser uni o bilateral, sólo involucra a la primera branquia aunque potencialmente podría también afectar 
al opérculo. El nivel afectado es cualquier sector (uno o varios) donde se encuentre cartílago hialino y hueso. El grado de severidad es máximo, porque corresponde a una pérdida de tejido epitelial y cartilaginoso y su transformación a tejido fibrilar denso. Parece ser un problema crónico que está latente en los peces y que tarda en expresarse.

Los niveles de $\mathrm{Ca}, \mathrm{P}$ y $\mathrm{Zn}$ de los salmones deformados están en el rango de normalidad. Bruno \& Poppe (1966) describen un cuadro histológico con hiperplasia de laminillas y fusión de ellas cuando la calidad del agua es deficiente. Además estos autores describen necrosis de laminillas primarias y secundarias cuando los peces han sido expuestos a niveles altos de formalina o acidificación del agua. En nuestro estudio se observaron imágenes histológicas similares. Como es sabido, la cresta neural asociada con el rombómero 2 migra hacia el primer arco. La del rombómero 4 va al segundo arco y la del rombómero 6 al tercero. Algunas crestopatias pueden ser producidas por problemas de manejo al estado de ova (temperatura elevada de las aguas) y que se expresa en distintos momentos de la vida del animal gatillados por algún estímulo externo. Lo que podría explicar que esta alteración afecte solo a la primera branquia adulta y que el cartílago hialino sea el principal afectado (Carlson, 2005). Normalmente el cartílago está constituido por células, matriz de fibras colágenas y una matriz extracelular de coindritin sulfato (Venegas, 2000; 2003). En esta patología aumenta la vascularización, disminuye hasta desaparecer la matriz extracelular de condroitin sulfato y avanza la matriz fibrilar hasta hacer desaparecer al cartílago (Ramírez, 2005). Se pudo evidenciar una importante contaminación de las branquias con parásitos, probablemente hifas de hongos que se ramifican y envuelven las laminillas branquiales, esto podría ser una causa secundaría que gatillaría la expresión de la deformación branquial, lo cual concuerda con lo descrito por Roberts para las branquiomicosis producidas por Saprolegnia.

De acuerdo a autores como Kinkelin et al., se debe considerar la importancia de factores ambientales tales como la calidad del agua, acidosis del agua y presencia de hon- gos, porque ellos pueden generar problemas de metaplasias con acortamiento de los filamentos branquiales, aumento de mucus y adherencia de estos filamentos entre sí, similar a lo descrito en este estudio. Es probable que estos signos produzcan pérdida de la movilidad de las laminillas branquiales y problemas mecánicos que van alterando músculos y ligamentos, como también fracturas del cartílago y hueso del arco branquial.

Es importante destacar que se encontraron cantidades muy altas de Zinc en los huesos. En los mamíferos está descrito que un exceso de Zinc puede conducir a una desmineralización de huesos, similar a lo encontrado en forma puntual en nuestro estudio (FAO).

En el estudio para microscopía electrónica en los cortes semifinos, se evidenciaron gran cantidad de ovas de hongos como también hifas. En los cortes ultrafinos se detectó una importante cantidad de bacterias con cápside, muchas células necróticas, autólisis de células de filamentos branquiales y macrófagos en degeneración, lo cual indica una reacción del organismo insuficiente para eliminar los múltiples agentes presentes en las branquias.

Los daños morfológicos de la estructura de las branquias, debido a la exposición a suspendidos, metales, sólidos y otras sustancias tóxicas, interfieren con el crecimiento, la alimentación, y desarrollo normal del individuo; por lo que estos cambios son considerados como buenos indicadores y de importancia ecológica usado frecuentemente como biomarcador (Viarengo et al., 2007).

\section{CONCLUSIÓN}

Los peces tendrían una susceptibilidad génica a la deformación branquial, ya que, es siempre la primera branquia la afectada, luego por factores externos tales como calidad del agua, contaminantes, bacterias y hongos, esta malformación se expresaría generando la patología que muestran los ejemplares estudiados.

ROA, I.; CASTRO, R. \& ROJAS, M. Gill deformation in salmonids: macroscopic, histological, ultrastructural and elements analysis. Int. J. Morphol., 29(1):45-51, 2011.

SUMMARY: Gills act as the respiratory organ in the respiration process in fish. They are considered among the most delicate body structures of teleost fish as they are subject to damage from any irritant, which are the most frequent and significant causes of their pathological changes. The objective of this study is to characterize gill alterations from the anatomical and histological standpoint, and to determine levels of $\mathrm{Ca}, \mathrm{P}$ and $\mathrm{Zn}$ in bone tissue of the spine and skull of affected salmon. For purposes of this study 47 salmon were used in two groups: control and deformation, subjected to complete histological, ultrastructural and element inspection. Abnormalities were observed in both the anatomical and histological context and extensive presence of bacteria and fungi affecting mainly the first arc were found. Therefore, we can conclude that these fish have a genetic susceptibility to gill deformation.

KEY WORDS: Salmonids; Gills; Deformation. 
ROA, I.; CASTRO, R. \& ROJAS, M. Deformación de branquias en salmónidos: Análisis macroscópico, histológico, ultraestructural y de elementos. Int. J. Morphol., 29(1):45-51, 2011.

\section{REFERENCIAS BIBLIOGRÁFICAS}

Bernet, D.; Schmidt, H.; Meier, W.; Bukhardt-Holm, P. \& Wahli, T. Histopathology in fish: Proposal for a protocol to assess aquatic pollution. J. Fish Dis., 22:2534, 1999.

Bruno, D. \& Poppe, T. A color atlas of salmonid diseases. Academic Press, London, 1996.

Carlson, B. Embriología humana y biología del desarrollo. Elsevier, Madrid, 2005. pp.317-35.

FAO, 2010. Disponible en: http://www.fao.org/DOCREP/ 003/T0700S/T0700S08.htm

Giari, L.; Manera, M.; Simoni, E. \& Dezfuli, B. S. Cellular alterations in different organs of European sea bass Dicentrarchus labrax (L.) exposed to cadmium. Chemosphere, 67:1171-81, 2007.

González, G. \& Valladolid, M. Aspectos biológicos, anatomía microscópica y enfermedades infecciosas de los salmónidos. Madrid, 1998.

Hanken, J. \& Wassersug, R. J. The visible skeleton. Funct. Photog., 16:22-6, 1981.

Kinkelin, P; Michel, C. \& Ghittino, P. Tratado de las enfermedades de los peces. Acribia, Madrid, 1991.353pp.

Ramírez, E. Estudio morfológico y análisis de minerales de la mandíbula inferior de salmones del Atlántico (Salmo salar) adultos con deformación mandibular provenientes de Escocia. Tesis para Optar al título de Médico Veterinario. Universidad de Chile, Chile. 2005.

Roberts, R. Patología de los peces. University of Stirling, Scotland, 1981. pp.75-80.

Venegas, F. Estudio histopatológico de la deformación mandibular en salmones del Sur de Chile. Tesis para Optar al título de Médico Veterinario. Universidad de Chile, Chile 2000.

Venegas, F.; Montiel, E.; Forno, P. \& Rojas, M. Histology of the jaw deformation in salmon of Southern Chile (Salmo salar). Int. J. Morphol., 21(3):211-9, 2003.

Viarengo, A.; Lowe, D.; Bolognesi, C.; Fabbri, E. \& Koehler, A. The use of biomarkers in biomonitoring: A 2-tier approach assessing the level of pollutant- induced stress syndrome in sentinel organisms. Comp. Biochem. Physiol. C Toxicol. Pharmacol., 146:281300, 2007.

Dirección para correspondencia:

Prof. Dra. Mariana Rojas Rauco Laboratorio de Embriología Comparada

Programa de Anatomía y Biología del Desarrollo Facultad de Medicina, ICBM Universidad de Chile

CHILE

E-mail: drarojas@hotmail.com

Recibido : 16-11-2010

Aceptado: 18-12-2010 